Bài báo khoa học

\title{
Đánh giá xu thế biến động của độ cao và chu kỳ sóng tại khu vực vịnh Bắc Bộ thuộc vùng biển ven bờ Việt Nam
}

\author{
Hoàng Trung Thành ${ }^{1}$, Nguyễn Trung Thành ${ }^{2 *}$ \\ ${ }^{1}$ Viện Nghiên cứu Biển và Hải đảo, Tổng cục Biển và Hải đảo Việt Nam; \\ thanhphutho2002@gmail.com \\ ${ }^{2}$ Trung tâm Quy hoạch và Điều tra tài nguyên - môi trường biển khu vực phía Bắc, Tổng \\ cục Biển và Hải đảo Việt Nam; thanhnt2212@gmail.com \\ *Tác giả liên hệ: thanhnt2212@gmail.com; Tel.: +94-904695966
}

Ban biên tập nhận bài: 23/11/2021; Ngày phản biện xong: 30/12/2021; Ngày đăng bài: $25 / 2 / 2022$

Tóm tắt: Nghiên cứu này tập trung vào việc tính toán, đánh giá xu thế biến đổi độ cao và chu kỳ sóng có nghĩa tại 05 điểm đại diện trên vịnh Bắc Bộ, cách bờ biển Việt Nam khoảng 24 hải lý $(44 \mathrm{~km})$. Việc tính toán xu thế được dựa trên các kết quả tính toán trường sóng trong 20 năm (2000-2019) ở khu vực Vịnh Bắc Bộ bằng mô hình SWAN sau khi đã kiểm định với số liệu quan trắc. Các kết quả tính toán tại 05 điểm này cho thấy các yếu tố sóng đều có xu hướng gia tăng, trong đó độ cao sóng có nghĩa cực đại trung bình các tháng trong năm gia tăng trong khoảng từ $0,0026 \mathrm{~m} /$ năm đến $0,0285 \mathrm{~m} / \mathrm{năm}$, độ cao sóng có nghĩa trung bình năm gia tăng trong khoảng từ $0,0004 \mathrm{~m} /$ năm đến $0,0046 \mathrm{~m} / \mathrm{năm}$, chu kỳ sóng có nghĩa trung bình năm gia tăng trong khoảng từ $0,0003 \mathrm{~s} /$ năm đến $0,0176 \mathrm{~s} / \mathrm{năm}$.

Từ khoá: Mô hình SWAN; Xu thế biến đổi độ cao và chu kỳ sóng; Vịnh Bắc Bộ.

\section{Mở đầu}

Các yếu tố hải văn nói chung và sóng biển nói riêng có tác động mạnh đến các công trình trên và ven biển, các phương tiện giao thông đường biển, các hoạt động kinh tế trên biển. Chính vì vậy từ lâu sóng biển đã được nghiên cứu trên nhiều phương diện khác nhau. Việc phân tích, đánh giá xu thế biến đổi các yểu tố sóng đã được nghiên cứu ở nhiều nơi trên thế giới. Từ năm 1970, Waldel đã tập trung vào việc phân tích sự thay đổi của chế độ sóng khí hậu ở Bắc Đại Tây Dương, thông qua số liệu độ cao sóng của 09 trạm đo từ năm 1950-1967, [1] cho rằng có sự thay đồi đáng kể về độ cao sóng trung bình giữa các năm. Trong những năm tiếp theo, cũng có nhiều nghiên cứu tập trung vào việc đánh giá xu thế thay đổi độ cao sóng, các kết quả nghiên cứu cho thấy xu thế tăng đối với cả độ cao sóng trung bình và độ cao sóng cực trị ở hẩu hết các đại dương trên thế giới [2-9].

Ở Biển Đông, cũng có một số nghiên cứu đối với xu thế biến đổi độ cao sóng có nghĩa, trong đó ở khu vực giữa Biển Đông độ cao sóng Hs90 có tốc độ tăng trung bình khoảng 0,011 $\mathrm{m} /$ năm, độ cao sóng có nghĩa trung bình có xu thế tăng trung bình khoảng $0,0152 \mathrm{~m} / \mathrm{năm}$ giai đoạn 1988 đến 2011 [10-12].

Ở Việt Nam, việc nghiên cứu tính toán dự báo sóng cũng đã được quan tâm nghiên cứu, đặc biệt là việc áp dụng mô hình SWAN trong các tính toán ở khu vực Biển Đông [13-14]. Việc nâng cao độ chính xác của mô hình thông qua việc áp dụng các công cụ hiện đại như việc hiệu chỉnh mô hình tự động [15], hay áp dụng đồng hóa số liệu cũng đã được quan tâm nghiên cứu [16-18]. Tuy nhiên, việc đánh giá xu thế biến đổi độ cao sóng ở khu vực ven bờ 
Việt Nam nói chung và khu vực Vịnh Bắc Bộ nói riêng vẫn chưa được quan tâm đúng mức. Vì vậy, nghiên cứu này tiến hành mô phỏng trường sóng ở khu vực Vịnh Bắc Bộ trong 20 năm (2000-2019) và trích ra các điểm ở vùng ven biển Việt Nam nhằm đánh giá xu thế biến động của độ cao sóng từ đó thấy được tác động của biến đổi khí hậu tới khu vực này.

\section{Phương pháp và số liệu tính toán}

\subsection{Mô hình sóng và số liệu đầu vào}

Nghiên cứu sử dụng mô hình tính sóng SWAN phiên bản 41.10 để tính toán mô phỏng trường sóng. Đây là mô hình tính toán sóng thế hệ ba [19], tính toán phổ sóng hai chiều bằng cách giải phương trình cân bằng tác động sóng có tính tới sự lan truyền sóng từ vùng nước sâu vào vùng nước nông ven bờ, đồng thời trao đổi năng lượng với gió thông qua hàm nguồn cùng với sự tiêu tán năng lượng sóng [20-21]. Trong mô hình SWAN các sóng được mô tả bằng phổ mật độ tác động sóng hai chiều. Phương trình cân bằng phổ mật độ tác động cơ bản được sử dụng trong những điều kiện phi tuyến cao. Trong mô hình SWAN phổ mật độ tác động $\mathrm{N}(\sigma, \theta)$ được chú ý hơn bởi vì, khi có mặt dòng chảy mật độ tác động được bảo toàn trong khi phổ mật độ năng lượng thì không [22]. Các biến độc lập là tần số $\sigma$ và hướng sóng $\theta$. Mật độ tác động được tính bằng mật độ năng lượng chia cho tần số.

Địa hình là yếu tố quan trọng bậc nhất của mô hình thủy động lực nói chung và tính toán sóng nói riêng. Độ chính xác của mô hình phụ thuộc rất lớn vào số liệu địa hình, đặc biệt là vùng ven bờ. Chính vì vậy việc thu thập và xử lý số liệu địa hình đóng vai trò quan trọng, để đảm bảo độ chính xác của địa hình, nhóm nghiên cứu tiến hành thu thập các loại số liệu bao bồm: Độ sâu và đường bờ trên toàn Biển Đông được thu thập từ nguồn số liệu ETOPO của NOAA [23] và các số liệu địa hình chi tiết tại khu vực gần bờ của các đợt điều tra khảo sát biển trong vùng nghiên cứu [24]. Từ các số liệu địa hình này nghiên cứu sử dụng phần mềm ADCIRC của SMS phiên bản 10.0 [25] để tạo lưới tính phi cấu trúc với bước lưới ở khu vực gần bờ là $3 \mathrm{~km}$ và thưa dần ra ngoài khơi, tổng số ô lưới là 5.365 . Có 2 biên lỏng là biên cửa Vịnh Bắc Bộ (1) và eo biển Quỳnh Châu (2). Phạm vi, lưới tính và địa hình của mô hình thể hiện trên hình $1 \mathrm{a}-1 \mathrm{~b}$.
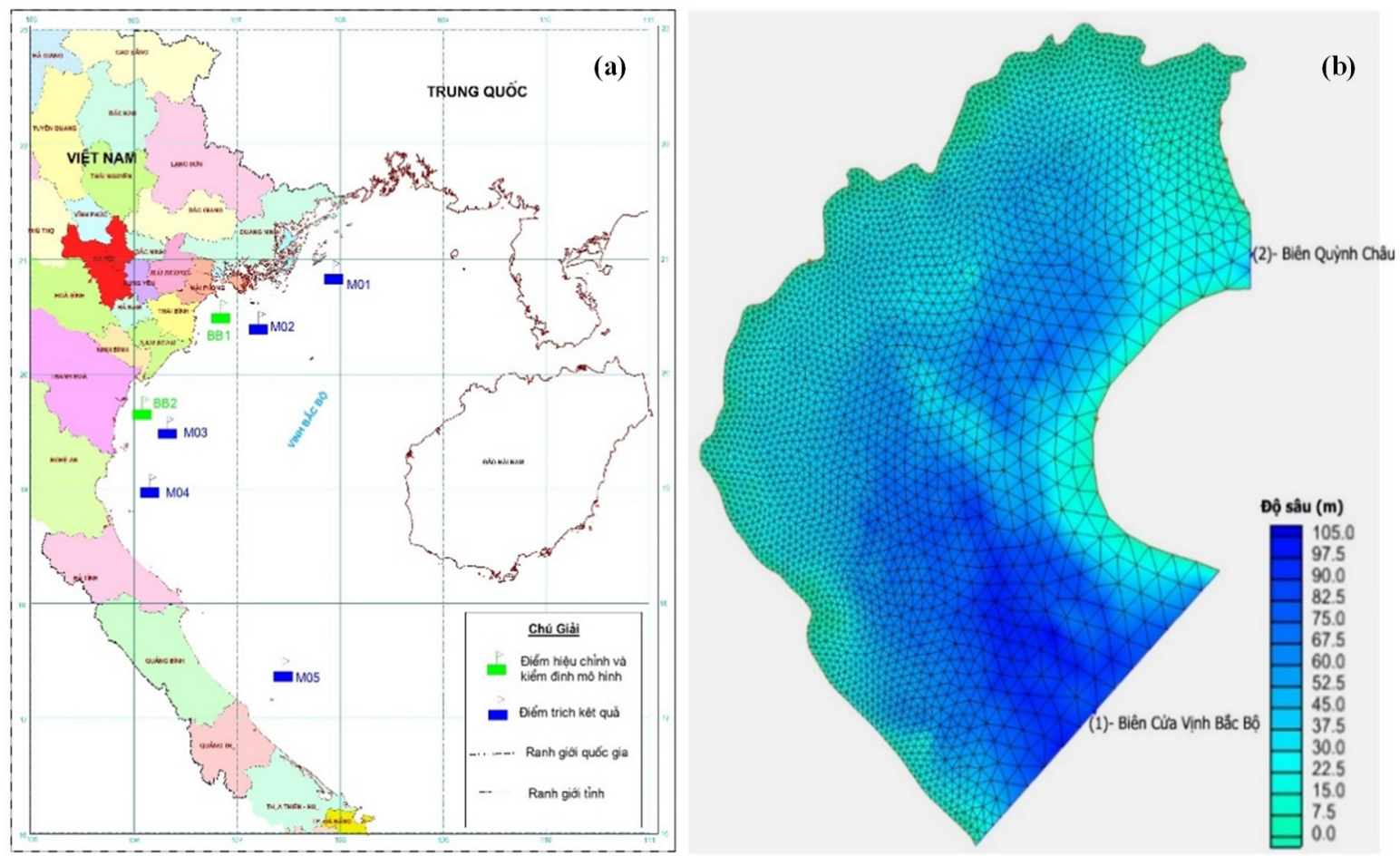

Hình 1. Phạm vi (a), lưới tính và địa hình (b) cho mô hình tại khu vực nghiên cứu. 
Số liệu biên trên mặt: là trường gió tái phân tích toàn cầu CFSv2 của Trung tâm Dự báo Môi trường Quốc Gia Mỹ (NCEP) [26-27]. Số liệu tại các biên mở (biên 1-2): là độ cao, chu kỳ và hướng sóng được trích ra từ số liệu sóng tái phân tích toàn cầu của ECMWF [28].

Trong nghiên cứu này, số liệu quan trắc tại trạm $\mathrm{BB} 1$ và $\mathrm{BB} 2$ được sử dụng để hiệu chỉnh và kiểm định mô hình. Tại trạm $\mathrm{BB} 1$ đo vào 02 đợt, trong đó đợt 1 : từ 0 giờ ngày 18/6/2019 đến 23 giờ 24/6/2019 với tổng số 168 số liệu, 01 số liệu/01 giờ; đợt 2: từ 19 giờ ngày $3 / 11 / 2019$ đến 19 giờ $10 / 11 / 2019$ với tổng số 336 số liệu, 01 số liệu/ 0,5 giờ. Tại trạm $\mathrm{BB} 2$ đo vào 02 đợt, trong đó đợt 1 : từ 0 giờ ngày 6/8/2019 đến 23 giờ $12 / 8 / 2019$ với tổng số 168 số liệu, 01 số liệu/01 giờ; đợt 2 : từ 13 giờ ngày 12/11/2019 đến 13 giờ 30 phút 19/11/2019 với tổng số 337 số liệu, 01 số liệu/0,5 giờ [29].

\section{2. Đánh giá sai số}

Trước khi tiến hành tính toán mô phỏng, mô hình SWAN đã được hiệu chỉnh và kiểm định thông qua đánh giá sai số các sai số sau:

- Sai số trung bình (ME)

Công thức tính sai số trung bình (ME - Mean Error) có dạng như sau:

$$
\mathrm{ME}=\frac{1}{\mathrm{k}} \sum_{\mathrm{i}=1}^{\mathrm{k}}(\text { for }(\mathrm{i})-\mathrm{obs}(\mathrm{i}))
$$

Trong đó obs (i) là giá trị quan trắc tại thời điểm i, for (i) là giá trị dự báo tương ứng tại thời điểm $\mathrm{i}$, và $\mathrm{k}$ là số lượng các giá trị quan trắc trong chuỗi quan trắc. Giá trị của $\mathrm{ME}$ nằm trong khoảng $(-\infty,+\infty)$. ME cho biết xu hướng lệch trung bình của giá trị dự báo so với giá trị quan trắc, nhưng không phản ánh độ lớn của sai số. ME dương cho biết giá trị dự báo thiên cao so với giá trị quan trắc và ngược lại. Mô hình được xem là "hoàn hảo" (không thiên lệch về một phía nào cả) nếu $\mathrm{ME}=0$.

- Sai số tuyệt đối trung bình (MAE)

Công thức tính sai số tuyệt đối trung bình (MAE-Mean Absolute Error) có dạng như sau:

$$
\mathrm{MAE}=\frac{1}{\mathrm{k}} \sum_{\mathrm{i}=1}^{\mathrm{k}} \mid \text { for }(\mathrm{i})-\operatorname{obs}(\mathrm{i}) \mid
$$

Trong đó | | là viết tắt của hàm trị tuyệt đối. Giá trị MAE nằm trong khoảng $(0,+\infty)$. MAE biểu thị biên độ trung bình của sai số mô hình nhưng không nói lên xu hướng lệch của giá trị dự báo và quan trắc. Khi $\mathrm{MAE}=0$, giá trị của mô hình hoàn toàn trùng khớp với giá trị quan trắc, mô hình được xem là "lý tưởng". Thông thường MAE được sử dụng cùng với $\mathrm{ME}$ để đánh giá độ tin cậy. Chẳng hạn, nếu MAE của sản phẩm khác biệt hẳn so với ME thì việc hiệu chỉnh là hết sức mạo hiểm. Trong trường hợp ngược lại, khi mà $\mathrm{MAE}$ và $\mathrm{ME}$ tương đối "sát" với nhau thì có thể dùng ME để hiệu chỉnh sản phẩm dự báo một cách đáng tin cậy.

- Sai số trung bình quân phương (RMSE)

Công thức tính sai số bình phương trung bình quân phương (RMSE - Root Mean Square Error) có dạng như sau:

$$
\operatorname{RMSE}=\sqrt{\frac{1}{\mathrm{k}} \sum_{\mathrm{i}=1}^{\mathrm{k}}(\text { for }(\mathrm{i})-\mathrm{obs}(\mathrm{i}))^{2}}
$$

Sai số trung bình quân phương là một trong những đại lượng cơ bản và thường được sử dụng phổ biến cho việc đánh giá kết quả của mô hình dự báo số trị. Người ta thường hay sử dụng đại lượng sai số trung bình quân phương (RMSE) biểu thị độ lớn trung bình của sai số. RMSE rất nhạy với những giá trị sai số lớn. RMSE không chỉ ra độ lệch giữa giá trị dự báo và giá trị quan trắc. Giá trị của $\mathrm{RMSE}$ nằm trong khoảng $(0,+\infty)$.

\subsection{Phwơng pháp xác định xu thế}

Biến thiên theo thời gian của độ cao sóng được xác định theo phương pháp phân tích xu thế (phân tích trend) [30]. Mối quan hệ giữa độ cao sóng và thời gian được xác định thông qua phương trình hồi quy tuyến tính dạng:

$$
y=a x+b
$$


Trong đó $a=\frac{\sigma_{y}}{\sigma_{x}} r, b=m_{y}-a m_{x}, r=\frac{\frac{\sum_{i=1}^{n} x_{i} y_{i}}{n}-m_{x} m_{y}}{\sigma_{x} \sigma_{y}}, m_{x}=\frac{\sum_{i=1}^{n} x_{i}}{n}, D_{x}=\frac{\sum_{i=1}^{n} x_{i}^{2}}{n}-$ $m_{x}^{2}, \sigma_{x}=\sqrt{D_{x}}, m_{y}=\frac{\sum_{i=1}^{n} y_{i}}{n}, D_{y}=\frac{\sum_{i=1}^{n} y_{i}^{2}}{n}-m_{y}^{2}, \sigma_{y}=\sqrt{D_{y}}$, n là độ dài của chuỗi số liệu.

\section{Kết quả và thảo luận}

\subsection{Kết quả hiệu chỉnh và kiểm định mô hình}

Có rất nhiều tham số có thể được đưa vào để hiệu chỉnh mô hình SWAN, trong nghiên cứu này chỉ tập trung vào các tham số đối với sóng nước sâu đó là các tham số: CDS2 - tốc độ tiêu tán sóng do sóng bạc đầu; powst - tỉ lệ giữa độ dốc phổ sóng thông thường với độ dốc phổ sóng Pierson-Moskowitz; powk - tî lệ giữa số sóng thông thường với số sóng trung bình và tham số cutfr - tỉ lệ giữa tần số sóng cực đại và tần số sóng trung bình [15].

\subsubsection{Hiệu chỉnh mô hình}

Nghiên cứu sử dụng các chuỗi số liệu đo đạc đợt 1 tại trạm BB1 và BB2 [29] để hiệu chỉnh mô hình. So sánh giữa kết quả tính toán và thực đo tại các vị trí quan trắc thể hiện trên hình 2 và 3 cho thấy đối với cả độ cao và chu kỳ sóng đường biến trình đều khá trùng nhau cả về pha lẫn độ lớn. Tại một số thời điểm độ cao sóng có xu hướng cao hơn độ cao sóng thực đo đặc biệt là vào những giai đoạn gió mùa tây nam tăng cường, tại một số thời điểm độ cao sóng tính toán lại thấp hơn độ cao sóng thực đo. Tương tự, đối với chu kỳ sóng cũng có diễn biến gần giống so với độ cao sóng.

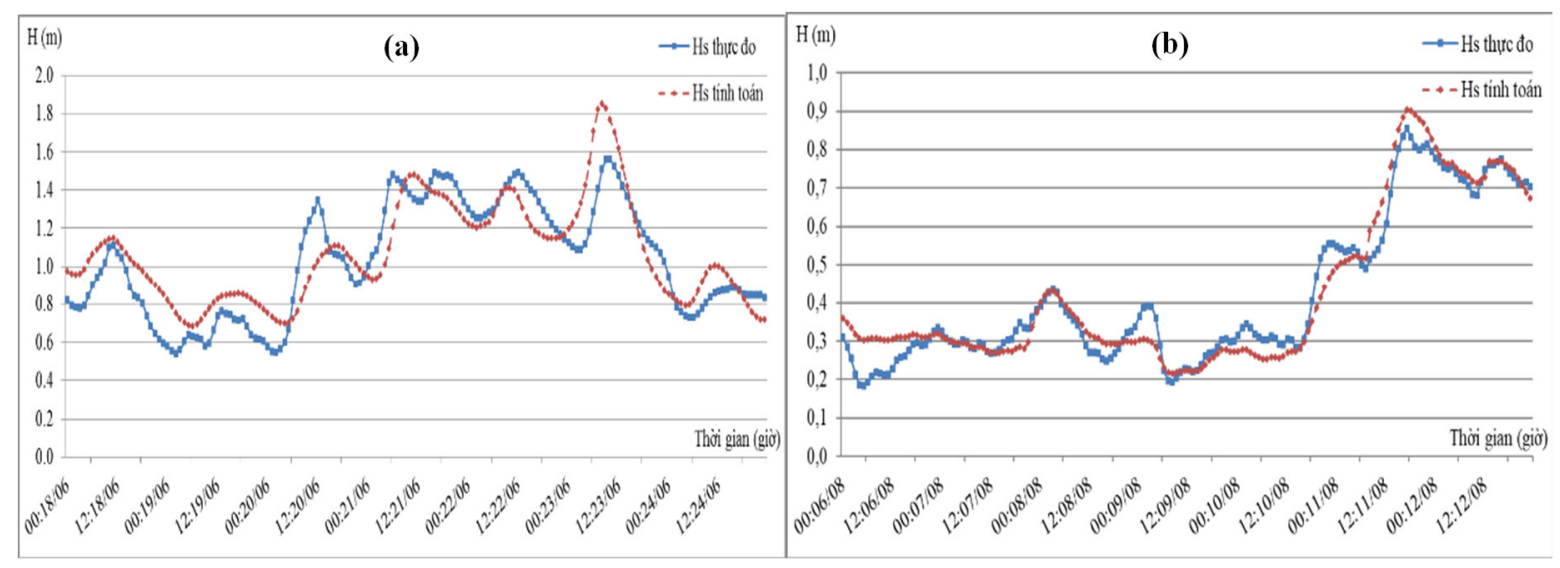

Hình 2. So sánh độ cao sóng tính toán và thực đo đợt 1: a) trạm BB1; b) trạm BB2.

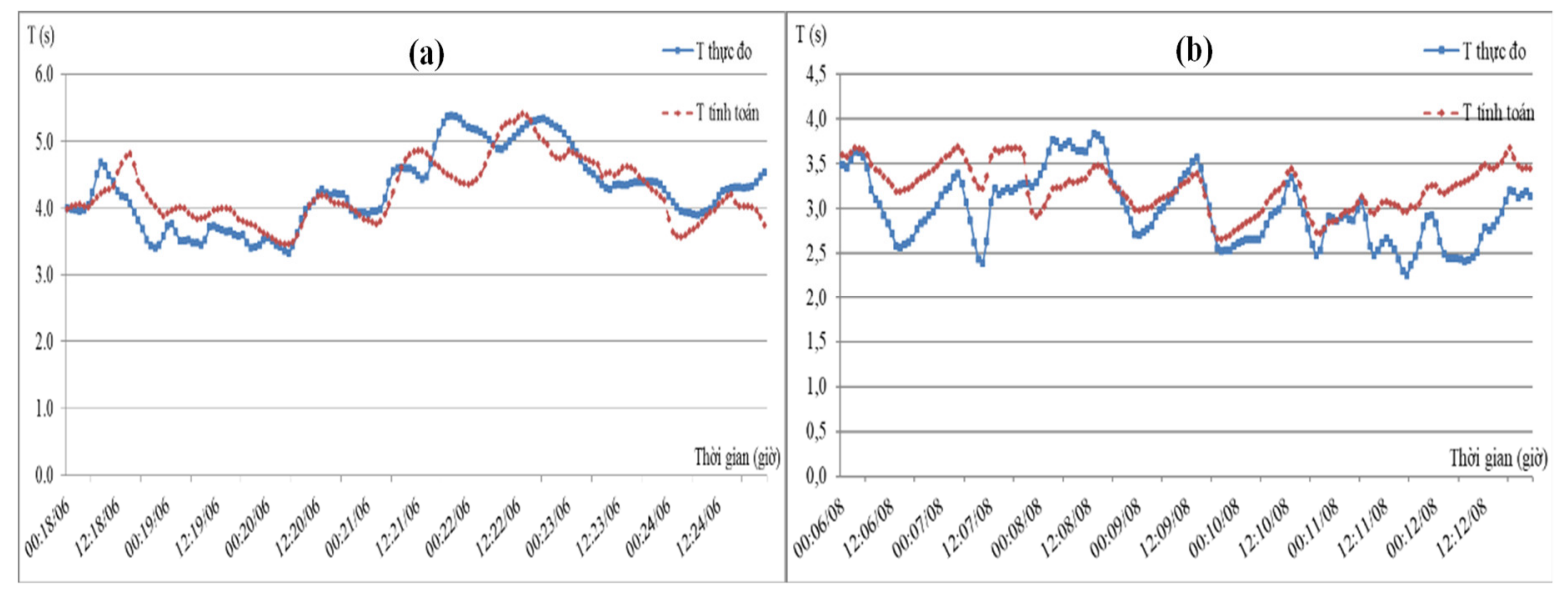

Hình 3. So sánh chu kỳ sóng tính toán và thực đo đợt 1: a) trạm BB1; b) trạm BB2. 
Để đánh giá sai số giữa kết quả tính toán và thực đo, các sai số ME (công thức 1), MAE (công thức 2), RMSE (công thức 3 ) được sử dụng. Kết quả trong bảng 1 cho thấy, đối với sai số $\mathrm{ME}$ độ cao sóng tính toán có xu hướng thiên cao, tuy nhiên mức thiên lệch khá nhỏ chỉ $0,04 \mathrm{~m}$ đối với trạm $\mathrm{BB} 1$ và $0,01 \mathrm{~m}$ đối với trạm $\mathrm{BB} 2$. Chu kỳ sóng có xu hướng thiên thấp tại trạm $\mathrm{BB} 1$ và thiên cao tại trạm $\mathrm{BB} 2$ với các giá trị tương ứng là $-0,02 \mathrm{~s}$ và $0,25 \mathrm{~s}$. Tương tự với sai số $\mathrm{MAE}$, các kết quả cho thấy biên độ trung bình của sai số giữa tính toán và thực đo của độ cao sóng là $0,13 \mathrm{~m}$ và $0,04 \mathrm{~m}$, chu kỳ là $0,28 \mathrm{~s}$ và $0,35 \mathrm{~s}$, tương ứng tại trạm $\mathrm{BB} 1$ và trạm BB2. Sai số RMSE lại thể hiện độ lớn trung bình của sai số giữa tính toán và thực đo và cho các giá trị tương ứng của độ cao sóng là $0,16 \mathrm{~m}$ và $0,05 \mathrm{~m}$, chu kỳ sóng là $0,35 \mathrm{~s}$ và $0,41 \mathrm{~s}$ tương ứng tại trạm $\mathrm{BB} 1$ và trạm $\mathrm{BB} 2$. Có thể thấy, sai số giữa tính toán và quan trắc độ cao và chu kỳ sóng khá nhỏ và chấp nhận được.

Bảng 1. Sai số giữa tính toán và thực đo tại các trạm quan trắc khi hiệu chỉnh.

\begin{tabular}{ccccc}
\hline \multirow{2}{*}{ Sai số } & \multicolumn{2}{c}{ Trạm BB1 } & \multicolumn{2}{c}{ Trạm BB2 } \\
\cline { 2 - 5 } & Độ cao sóng (m) & Chu kỳ sóng (s) & Độ cao sóng (m) & Chu kỳ sóng (s) \\
\hline ME & 0,04 & $-0,02$ & 0,01 & 0,25 \\
MAE & 0,13 & 0,28 & 0,04 & 0,35 \\
RMSE & 0,16 & 0,35 & 0,05 & 0,41 \\
\hline
\end{tabular}

\subsubsection{Kiểm định mô hình}

Nghiên cứu sử dụng các chuỗi số liệu đo đạc đợt 2 tại trạm BB1 và BB2 [29] để kiểm định mô hình. So sánh diễn biến độ cao, chu kỳ sóng tính toán và thực đo thể hiện trên hình 4 và 5 , tương ứng. Kết quả cho thấy, mặc dù có nhiều thời điểm độ cao và chu kỳ sóng tính toán còn thiên thấp và thiên cao so với thực đo, nhưng nhìn chung xu thế tương đối phù hợp cả về pha và độ lớn.

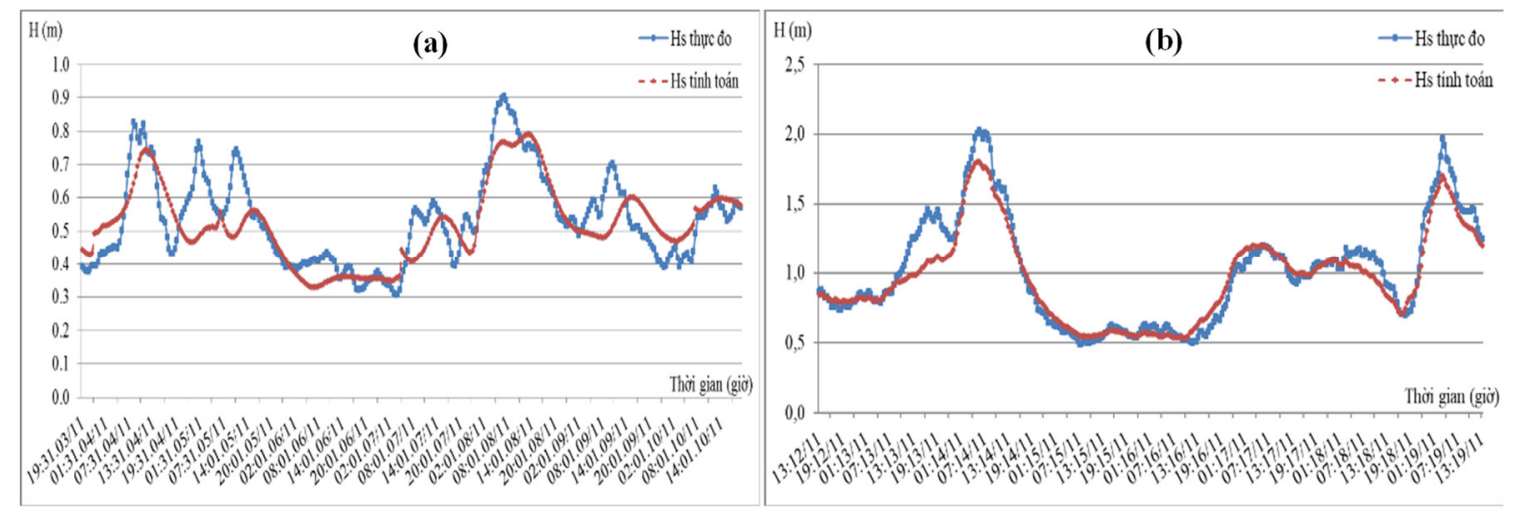

Hình 4. So sánh độ cao sóng tính toán và thực đo đợt 1: a) trạm BB1; b) trạm BB2.

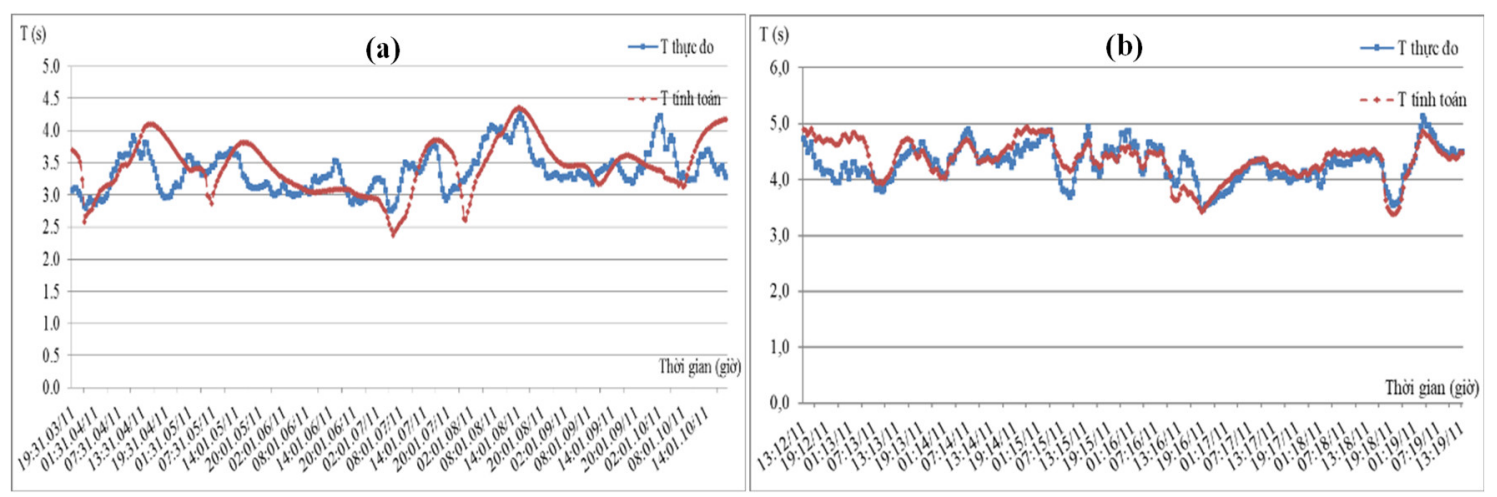

Hình 5. So sánh chu kỳ sóng tính toán và thực đo đợt 1: a) trạm $B B 1$; b) trạm BB2. 
Cũng tương tự như hiệu chỉnh mô hình, kiểm định mô hình cũng sử dụng các sai số $\mathrm{ME}$, MAE, RMSE để đánh giá sai số giữa kết quả tính toán và thực đo. Kết quả kiểm định trong bảng 2 cho thấy, đối với sai số $\mathrm{ME}$ độ cao sóng tính toán có xu hướng thiên thấp, tuy nhiên mức thiên lệch khá nhỏ chỉ $-0,02 \mathrm{~m}$ đối với trạm $\mathrm{BB} 1$ và $-0,04 \mathrm{~m}$ đối với trạm $\mathrm{BB} 2$. Chu kỳ sóng có $x u$ hướng thiên cao tại cả trạm $\mathrm{BB} 1$ và trạm $\mathrm{BB} 2$ với giá trị đều là $0,07 \mathrm{~s}$. Tương tự với sai số $\mathrm{MAE}$, các kết quả cho thấy biên độ trung bình của sai số giữa tính toán và thực đo của độ cao sóng là $0,06 \mathrm{~m}$ và $0,08 \mathrm{~m}$, chu kỳ là $0,31 \mathrm{~s}$ và $0,18 \mathrm{~s}$ tương ứng tại trạm $\mathrm{BB} 1$ và trạm BB2. Sai số RMSE lại thể hiện độ lớn trung bình của sai số giữa tính toán và thực đo và cho các giá trị tương ứng của độ cao sóng là $0,08 \mathrm{~m}$ và $0,11 \mathrm{~m}$, chu kỳ sóng là $0,38 \mathrm{~s}$ và $0,24 \mathrm{~s}$ tương ứng tại trạm $\mathrm{BB} 1$ và trạm $\mathrm{BB} 2$. Như vậy, có thể thấy sai số giữa tính toán và thực đo của độ cao và chu kỳ sóng khi kiểm định cũng khá nhỏ và chấp nhận được.

Bảng 2. Sai số giữa tính toán và thực đo tại các trạm quan trắc khi kiểm định.

\begin{tabular}{ccccc}
\hline \multirow{2}{*}{ Sai số } & \multicolumn{2}{c}{ Trạm BB1 } & \multicolumn{2}{c}{ Trạm BB2 } \\
& Độ cao sóng (m) & Chu kỳ sóng (s) & Độ cao sóng (m) & Chu kỳ sóng (s) \\
\hline ME & $-0,02$ & 0,07 & $-0,04$ & 0,07 \\
MAE & 0,06 & 0,31 & 0,08 & 0,18 \\
RMSE & 0,08 & 0,38 & 0,11 & 0,24 \\
\hline
\end{tabular}

Qua hiệu chỉnh và kiểm định mô hình ở trên có thể thấy, sai số của mô hình là chấp nhận được và bộ thông số sau khi hiệu chỉnh sẽ sử dụng để tính toán các tham số sóng trong mục 3.2 dưới đây.

\subsection{Kết quả tính toán $x u$ thế}

Với các kết quả hiệu chỉnh và kiểm định mô hình ở trên, nghiên cứu sử dụng các tham số đã lựa chọn được tiến hành tính toán trường sóng trong 20 năm từ 00 giờ ngày $01 / 01 / 2000$ đến 23 giờ ngày 31/12/2019 bằng mô hình $\mathrm{SWAN}$ với bước trích xuất kết quả là 01 số liệu/01 giờ tại tất cả các điểm lưới của mô hình. Để đánh giá xu thế biến động trường sóng ở vùng biển ven bờ Việt nam trong Vịnh Bắc Bộ, nghiên cứu lựa chọn 05 điểm để trích kết quả và tính toán thống kê đối với độ cao sóng có nghĩa Hs và chu kỳ sóng có nghĩa Ts, các kết quả thống kê được thể hiện như sau:

a) Xu thế biến động độ cao sóng có nghĩa cực đại trung bình các tháng trong năm (Hsmax)

Các kết quả tính toán được thể hiện trong hình 6 cho thấy Hsmax tại tất cả các điểm đều có xu hướng tăng với mức độ tăng trung bình tại tất cả các điểm là $0,0146 \mathrm{~m} / \mathrm{năm}$. Trong đó, điểm có mức độ gia tăng lớn nhất là điểm $\mathrm{M} 03$, với giá trị gia tăng là $0,0285 \mathrm{~m} / \mathrm{năm}$, điểm này nằm ở ngoài khơi vùng biển Sầm Sơn, Thanh Hóa. Điểm có mức độ gia tăng nhỏ nhất là điểm M05, với giá trị gia tăng là $0,0026 \mathrm{~m} / \mathrm{năm}$, điểm này nằm ở gần đảo Cồn Cỏ thuộc ngoài khơi tỉnh Quảng Trị. Như vậy, có thể thấy xu thế biến đổi độ cao sóng có nghĩa cực đại trung bình các tháng trong năm ở vùng biển này có hướng gia tăng có thể do tác động của biến đồi khí hậu.

b) Xu thế biến động độ cao sóng có nghĩa trung bình năm (Hstb)

Các kết quả tính toán đối Hstb trong hình 7 cũng tương tự như với Hsmax, trong đó tại tất cả các điểm Hstb đều có xu hướng tăng với mức độ tăng trung bình tại tất cả các điểm là $0,0022 \mathrm{~m} / \mathrm{năm}$. Trong đó, điểm có mức độ gia tăng lớn nhất là điểm M03, với giá trị gia tăng là $0,0046 \mathrm{~m} / \mathrm{năm}$, điểm này nằm ở ngoài khơi vùng biển Sầm Sơn, tỉnh Thanh Hóa. Điểm có mức độ gia tăng nhỏ nhất là điểm M05, với giá trị gia tăng là $0,0004 \mathrm{~m} / \mathrm{năm}$, điểm này nằm ở gần đảo Cồn Cỏ, tỉnh Quảng Trị. Như vậy, tác động của biến đổi khí hậu có thể là nguyên nhân làm cho độ cao sóng có nghĩa trung bình năm ở vùng biển này có xu hướng gia tăng. 


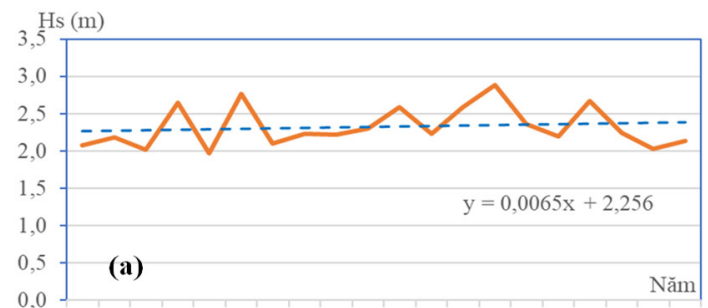

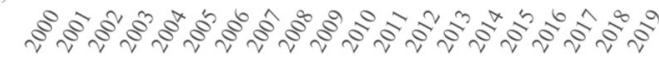
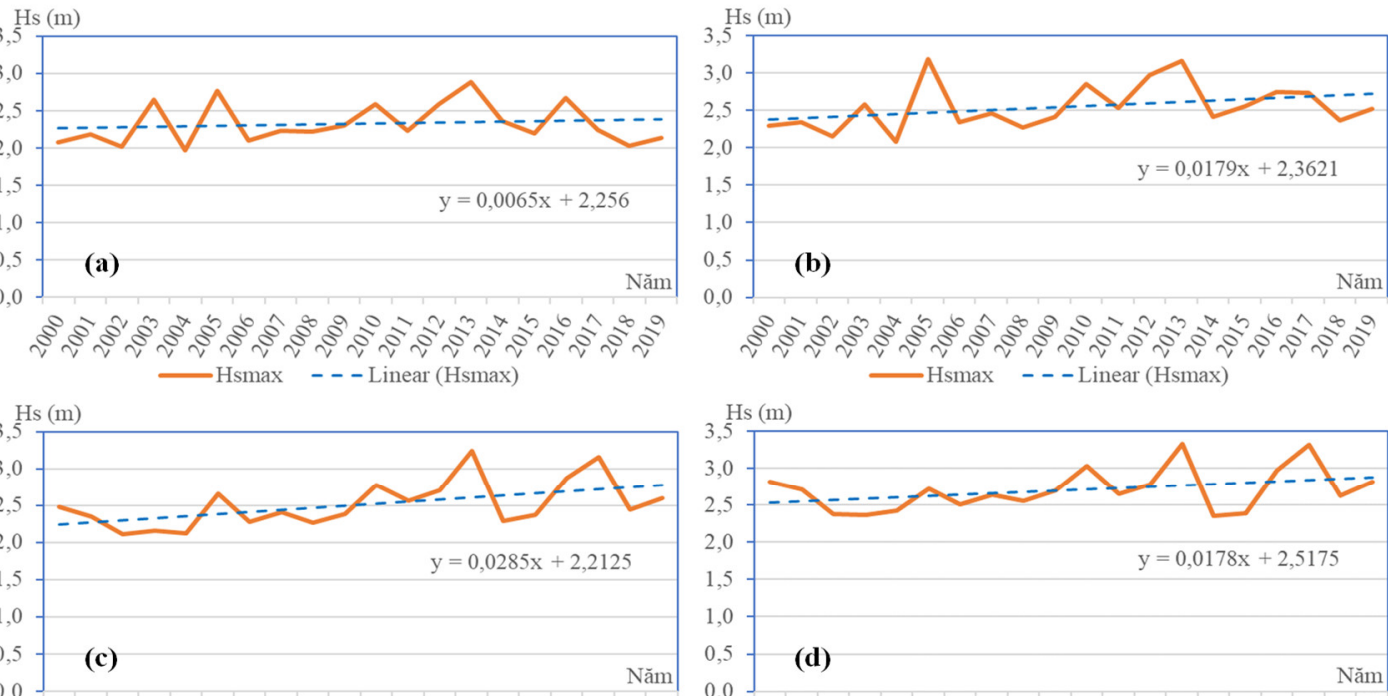

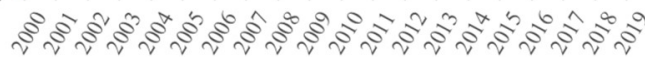
_-Hsmax - - -Linear (Hsmax)

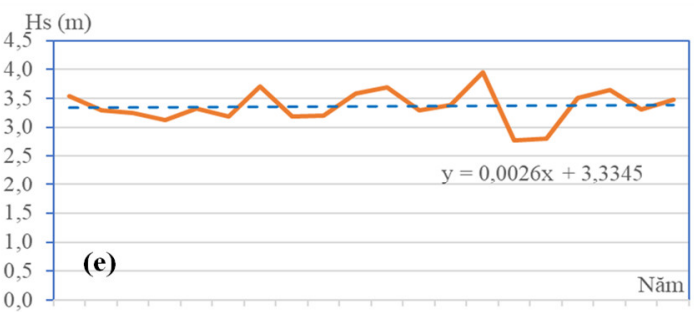

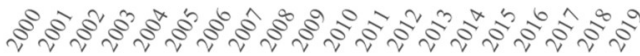

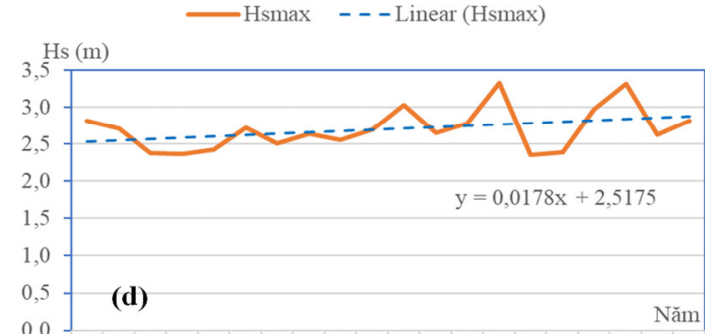

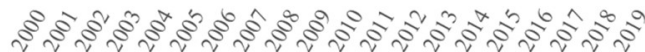
-Hsmax - - - Linear (Hsmax)

Hình 6. Xu thế biến động Hsmax từ năm 2000 đến 2019: a) M01; b) M02; c) M03; d) M04; e) M05.

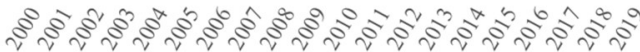

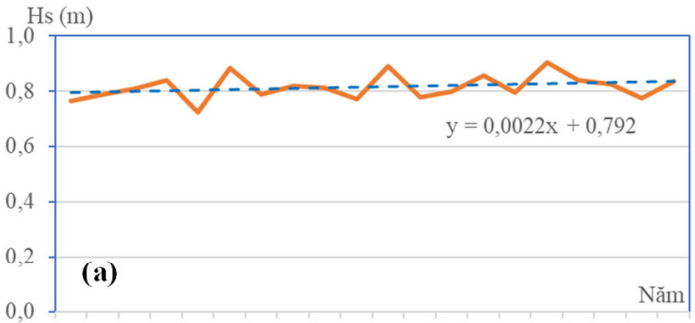

8.
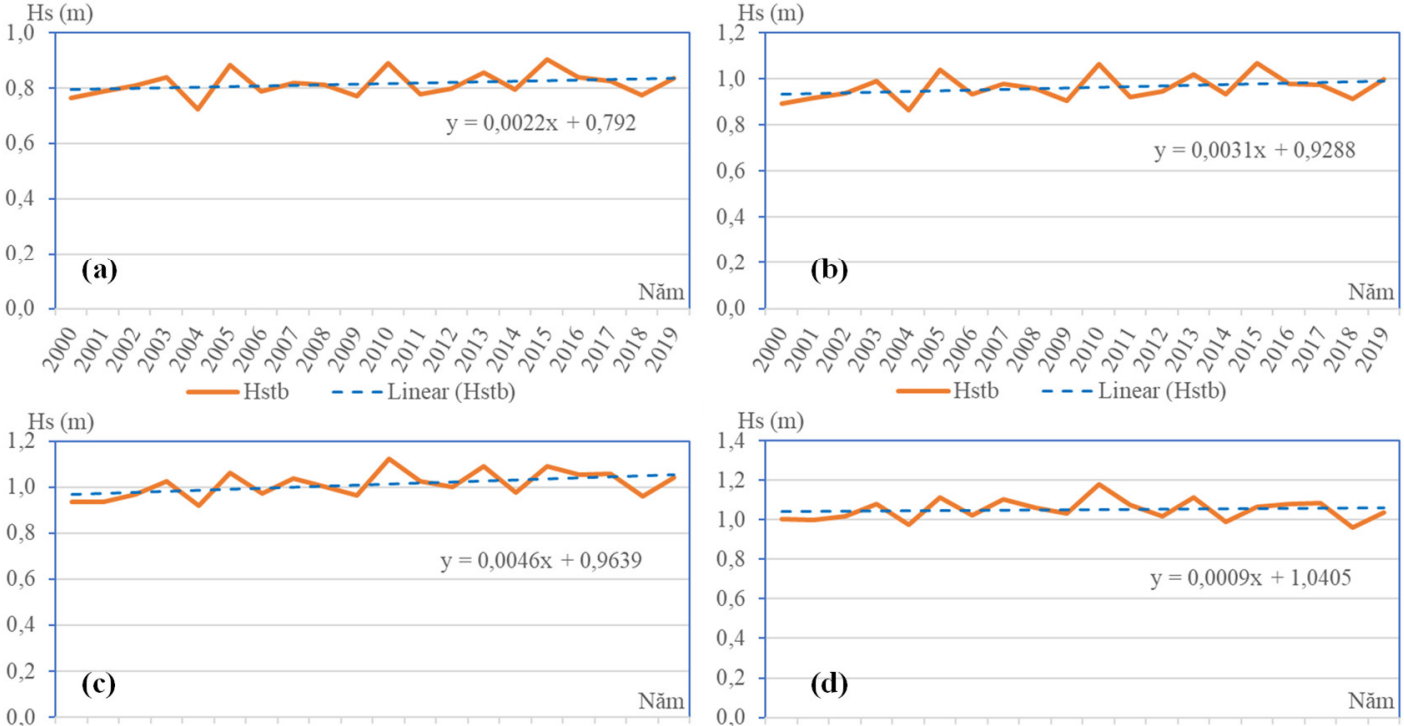

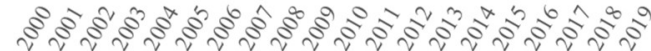

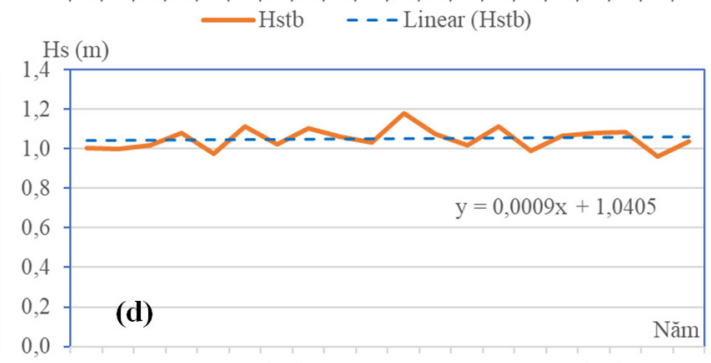

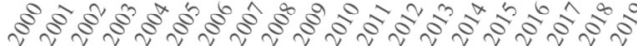

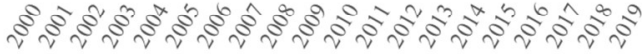

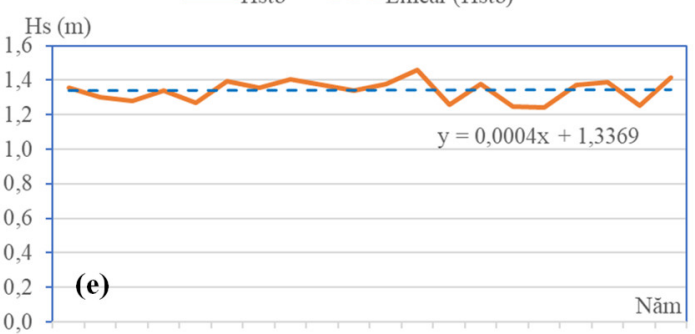

- Hstb - - - Linear (Hstb)

Hình 7. Xu thế biến động Hstb từ năm 2000 đến 2019: a) M01; b) M02; c) M03; d) M04; e) M05.

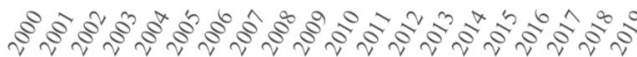
— Hstb - - - Linear (Hstb) 
c) Xu thế biến động chu kỳ sóng có nghĩa trung bình năm (Tstb)

Các kết quả tính toán đối Tstb trong hình 8 cho thấy tại tất cả các điểm đều có xu hướng tăng với mức độ tăng trung bình tại tất cả các điểm là $0,0059 \mathrm{~s} /$ năm. Trong đó, điểm có mức độ gia tăng lớn nhất là điểm M01, với giá trị gia tăng là $0,0176 \mathrm{~s} /$ năm, điểm này nằm ở ngoài khơi vùng biển tỉnh Quảng Ninh. Điểm có mức độ gia tăng nhỏ nhất là điểm M03, với giá trị gia tăng là $0,0003 \mathrm{~s} /$ năm, điểm này nằm ở vùng biển Sầm Sơn, tỉnh Thanh Hóa. Như vậy, có thể thấy tác động của biến đổi khí hậu có thể là nguyên nhân làm thay đổi chu kỳ sóng có nghĩa trung bình năm ở vùng biển này.
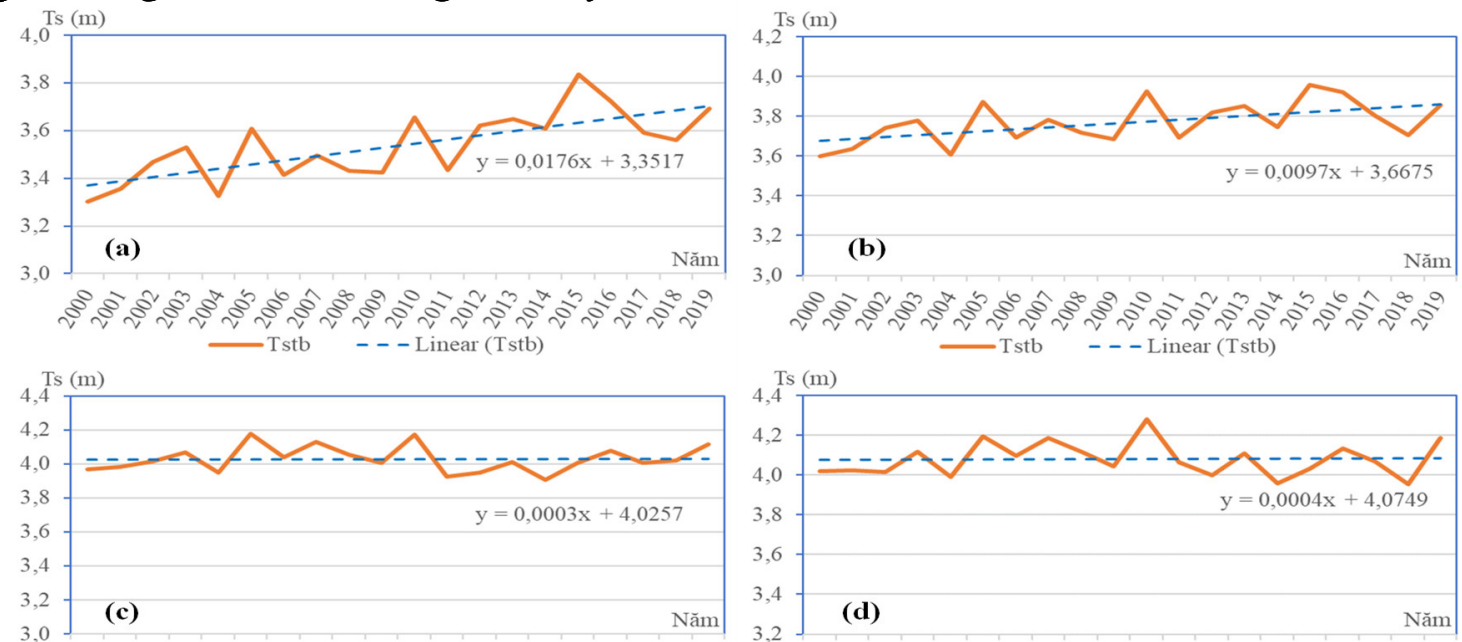

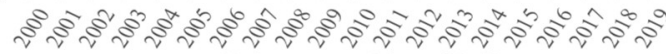
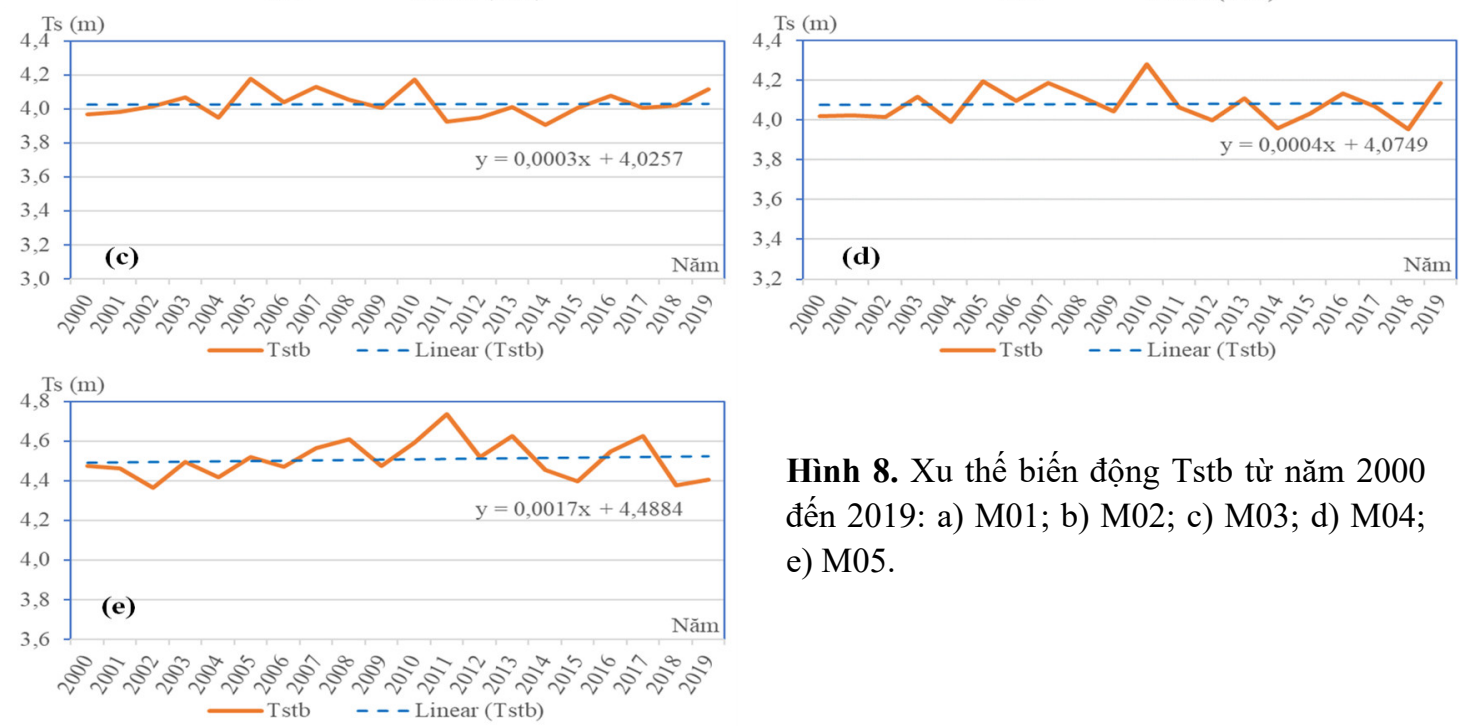

Hình 8. Xu thế biến động Tstb từ năm 2000 đến 2019: a) M01; b) M02; c) M03; d) M04; e) $\mathrm{M} 05$.

\section{Kết luận}

Việc hiệu chỉnh và kiểm định mô hình được thực hiện tại 02 vị trí với 02 chuỗi số liệu độc lập và được đánh giá thông qua các chỉ số $\mathrm{ME}, \mathrm{MAE}, \mathrm{RMSE}$ và dưới dạng biểu đồ. Các kết quả so sánh hiệu chỉnh và kiểm định tại trạm đo $\mathrm{BB} 1$ và $\mathrm{BB} 2$ ở khu vực Vịnh Bắc Bộ cho thấy các tham số lựa chọn là phù hợp và mô hình tính toán đủ độ tin cậy để áp dụng vào mô phỏng các yếu tố sóng trong khu vực.

Thông qua kết quả tính toán trường sóng trong 20 năm từ năm 2000 đến năm 2019 trên khu vực vịnh Bắc Bộ và kết quả phân tích tại 05 điểm đại diện, có thể thấy độ cao sóng có nghĩa cực đại trung bình tháng trong năm ở khu vực này cũng có xu hướng gia tăng. Với 05 điểm được lựa chọn để đánh giá xu thế cho thấy mức độ gia tăng trung bình tại 05 điểm này là $0,0146 \mathrm{~m} /$ năm, mức độ gia tăng lớn nhất là $0,0285 \mathrm{~m} /$ năm và mức độ gia tăng nhỏ nhất là $0,0026 \mathrm{~m} /$ năm. Độ cao sóng có nghĩa trung bình năm ở 05 điểm này có mức độ tăng trung bình là $0,0022 \mathrm{~m} /$ năm, mức độ gia tăng lớn nhất là $0,0046 \mathrm{~m} /$ năm và mức độ gia tăng nhỏ nhất là $0,0004 \mathrm{~m} /$ năm. Chu kỳ sóng có nghĩa trung bình có mức độ tăng trung bình tại 05 này điểm là $0,0059 \mathrm{~s} /$ năm, mức độ gia tăng lớn nhất là $0,0176 \mathrm{~s} /$ năm, mức độ gia tăng nhỏ nhất là $0,0003 \mathrm{~m} / \mathrm{năm}$.

Đóng góp của tác giả: Xây dựng ý tưởng nghiên cứu: H.T.T.; Lựa chọn phương pháp nghiên cứu: H.T.T.; N.T.T.; Mô hình hóa: N.T.T., Phân tích kết quả: H.T.T.; Chỉnh sửa bài báo: N.T.T. 
Lời cảm ơn: Nghiên cứu này được tài trợ bởi Đề tài "Nghiên cứu cơ sở khoa học xây dựng mạng lưới điều tra cơ bản và giám sát môi trường biển giai đoạn 2020-2030, tầm nhìn 2045 (ĐTĐL.CN-56/20)".

Lời cam đoan: Tập thể tác giả cam đoan bài báo này là công trình nghiên cứu của tập thể tác giả, chưa được công bố ở đâu, không được sao chép từ những nghiên cứu trước đây; không có sự tranh chấp lợi ích trong nhóm tác giả.

\section{Tài liệu tham khảo}

1. Walden, H. Long Term Variability. Proceeding of $4^{\text {th }}$ International Ship Structures Congress, Tokyo, 1970.

2. Wang, X.L.; Swail, V.R. Changes of extreme wave heights in northern hemisphere oceans and related atmospheric circulation regimes. J. Clim. 2001, 14(10), 22042221.

3. Wang, X.L.; Swail, V.R. Trends of Atlantic wave extremes as simulated in a 40-yr wave hindcast using kinematically reanalyzed wind fields. J. Clim. 2002, 15(9), 1020-1035.

4. Young, I.R.; Babanin, A. Global Trends in Wind Speed and Wave Height. Sciencexpress 2011, 332, 451-455.

5. Young, I.R. Investigation of trends in extreme value wave height and wind speed. Geophys. Res. Ocean 2012, 117, 1-13.

6. Shanas, P.R.; Kumar, V.S. Trends in surface wind speed and significant wave height as revealed by ERA-Interim wind wave hindcast in the Central Bay of Bengal. Climatol. 2015, 35, 2654-2663.

7. Kumar, P. Influence of climate variability on extreme ocean surface wave heights assessed from ERA-interim and ERA-20C, Climate, 2016.

8. Young, I.R.; Ribal, A. Multiplatform evaluation of global trends in wind speed and wave height. Science 2019, 19(364(6440)), 548-552.

9. Timmermans, B.W. Global Wave Height Trends and Variability from New Multimission Satellite Altimeter Products, Reanalyses, and Wave Buoys. Geophys. Res. Lett. 2020, 47(9), e2019GL086880.

10. Adekunle, O. Long-Term Variability of Extreme Significant Wave Height in the South China Sea. Adv. Meteorol. 2016, 2419353, pp. 21.

11. Wu, L.; Li, X. South China Sea Wave Height Trends Analysis Using 20CR Reanalysis. International Conference on Automatic Control and Information Engineering (ICACIE 2016), 2016.

12. Zheng, C. Trends in significant wave height and surface wind speed in the China Seas between 1988 and 2011. Oceanic Coastal Sea Res. 2017, 16, 717-726.

13. Điển, D.C.; Hùng, N.M. Calibration and verification of a storm wave model in the coastal zones of the East Sea. Tuyển tập công trình Hội nghị khoa học Cơ học Thuỷ Khí Toàn Quốc, 2006.

14. Hung, N.M.; Dien, D.C. Wave Energy Atlas in Vietnam. In Proceedings of the 3rd International Conference on Ocean Energy, Bilbao, Spain, 6-8 October 2010.

15. Thanh, N.T.; Huan, N.M.; Tien, T.Q. Application of automated calibration method to calibrate parameters in SWAN model using wave height data from satellite and MSP1 in Eastern Vietnam Sea. J. Marine Sci. Technol. 2017, 17(3), 271-278.

16. Thanh, N.T.; Huan, N.M.; Tien, T.Q. Application of data assimilation method for wave height in eastern vietnam sea by the Ensemble Kalman Filter. J. Marine Sci. Technol. 2018, 18(4), 358-367.

17. Thành, N.T.; Hà, D.T.; Tiến, D.Đ. Thử nghiệm đồng hoá số liệu độ cao sóng tại trạm phao và vệ tinh bằng phương pháp lọc Kalman tổ hợp. Tạp chí Khoa học và công nghệ Thủy lợi 2019, 55, 43-55. 
18. Thanh, N.T.; Lars, R.H.; Tien, D.D.; Huan, N.M. A Case Study of Wave Forecast Over South China Sea Using SWAN Model and Ensemble Kalman Filter Method. Oceanogr. Fish. 2020, 12(4), 555842.

19. The SWAN team. Swan user manual. Delft University of Technology, 2016.

20. Booij, N.; Ris, R.C.; Holthuijsen, L.H. A third-generation wave model for coastal regions: 1. Model description and validation. J. Geophys. Res. 1999, 104(C4), 76497666.

21. Ris, R.C.; Holthuijsen, L.H.; Booij, N. A third-generation wave model for coastal regions: 2. Verification. J. Geophys. Res. 1999, 104(C4), 7667-7681.

22. Whitham, G.B. Linear and Nonlinear Waves. Wiley, New York, 1974, pp. 636.

23. Smith, W.H.S.; Sandwell, D.T. Global seafloor topography from satellite altimetry and ship depth soundings. Science 1977, 277, 1957-1962.

24. Dương, N.Đ. Đề tài cấp nhà nước: Ô nhiễm dầu trên vùng biển Việt Nam và Biển Đông. Chương trình Khoa học và Công nghệ biển phục vụ phát triển bền vững kinh tế - xã hội, KC.09/06-10, 2011.

25. Environmental Modeling Research Laboratory. ADCIRC Analysis. Surface Water Modeling System, 2009.

26. Kalnay, E.; Kanamitsu, M.; Kistler, R.; Collins, W.; Deaven, D.; Gandin, L.; Iredell, M.; Saha, S.; White, G.; Woollen, J.; Zhu, Y.; Chelliah, M.; Ebisuzaki, W.; Higgins, W.; Janowiak, J.; Mo, K.C.; Ropelewski, C.; Wang, J.; Leetmaa, A.; Reynolds, R.; Jenne, R.; Joseph, D. The NCEP/NCAR 40-year reanalysis project. Bull. Am. Meteorol. Soc. 1996, 77(3), 437-472.

27. Saha, S. The NCEP Climate Forecast System Version 2. J. Clim. 2014, 27, 21852208.

28. http://apps.ecmwf.int/datasets Truy cập ngày 24/12/2020.

29. Trung tâm Quy hoạch và Điều tra tài nguyên - môi trường biển khu vực phía Bắc: Dự án Điều tra cơ bản tài nguyên - môi trường các bãi bồi ven biển phục vụ phát triển kinh tế biển và bảo vệ an ninh quốc phòng, 2019.

30. Tín, N.V.; Thịnh, N.N. Nghiên cứu xu thế biến đổi các yếu tố khí hậu, mực nước tại Bà Rịa - Vũng Tàu. Tạp chi Khí tượng Thủy văn 2012, 622, 13-16.

\title{
Evaluation of the wave height and period trends in the Gulf of Tonkin in the coastal area of Vietnam
}

\section{Hoang Trung Thanh ${ }^{1}$, Nguyen Trung Thanh ${ }^{2 *}$}

1 Vietnam Institute of Seas and Island, Vietnam Administration of Seas and Islands; thanhphutho2002@gmail.com

${ }^{2}$ Northern Center for Planning and Investigation of Marine Resources - Environment, Vietnam Administration of Seas and Islands; thanhnt2212@gmail.com

\begin{abstract}
This study focuses on evaluating the significal wave height and period trends at 05 representative locations in the Gulf of Tonkin, about 24 nautical miles (44 kilometers) from the coast of Vietnam. The simulation of trends are based on the wave field calculation results for 20 years (2000-2019) in the Gulf of Tonkin using the SWAN model after calibration and verification with observed data. The results at these 05 locations in the Gulf of Tonkin show that the wave factors tend to increase, in which the monthly average maximum significal wave height increases in the range of $0.0026 \mathrm{~m} /$ year to $0.0285 \mathrm{~m} /$ year, the mean annual significal wave height increases in the range of $0.0004 \mathrm{~m} /$ year to 0.0046 $\mathrm{m} /$ year, the mean annual significal wave period increases in the range of $0.0003 \mathrm{~s} /$ year to $0.0176 \mathrm{~s} /$ year.
\end{abstract}

Keywords: SWAN model; Wave height and period trend; Gulf of Tonkin. 